\title{
trabahonecessário
}

issn: $1808-799 \mathrm{X}$

ano 3 número $3-2005$

\section{SOBRE A GÊNESE E ESTADO ATUAL DOS CONFLITOS POLÍTICO-SOCIAIS NA COLOOMBIA}

Gaudêncio Frigotto entrevista Orlando Pulido Chaves[1].

\section{GF: ¿Qué explica el estado de guerra desde hace cuatro décadas en Colombia?}

OPC: En Colombia el desarrollo del capitalismo se inició hacia 1930, con base en una industria monopólica orientada a la producción textil y de alimentos que empleaba poca fuerza de trabajo asalariado dentro de la cual destacaba un alto porcentaje de mujeres. Entre 1930 y 1950 se dio el proceso de introducción de capital a la agricultura, por la vía de la lenta transformación de la gran hacienda de ganadería extensiva en hacienda capitalista, hecho que implicó un lento proceso de descomposición del campesinado y la articulación de formas "precapitalistas" de producción como la aparcería, el arrendamiento y el colonato, entre otras, a este tipo de desarrollo.

Para un país eminentemente agrario como el de entonces, esto significó la no resolución del problema del acceso a la tierra para los campesinos pobres y parcelarios, el desarrollo de una agricultura capitalista comercial orientada a la exportación y a la producción de materias primas para la industria (algodón, arroz, ajonjolí, sorgo, para citar algunos). Un caso particular lo constituyó el cultivo del café, el cual se orientó fundamentalmente a la exportación, mediante un modelo basado en la pequeña y la mediana propiedad, hecho que originó un proceso rápido de acumulación en la zona cafetera que se tradujo en una mejora significativa de las condiciones de vida de los productores y los habitantes de estas zonas del país.

Articulado a la agricultura comercial y a la economía cafetera se formó un importante sector de proletarios agrícolas transhumantes que recorrían el país, sobre todo en las épocas de siembra y recolección, vinculando estacionalmente a muchos campesinos parcelarios que por esta vía complementaban sus ingresos.

La lenta penetración del capital al campo implicó una lenta acumulación originaria expresada en un lento proceso de transformación del campesinado en fuerza de trabajo asalariado. La dureza de este proceso dio origen a la llamad "violencia" de finales de los años 40 y comienzos de los 50, cuando liberales y conservadores se trenzaron en una dura lucha por el poder, en función del tipo de desarrollo del capitalismo deseado para el país en el marco del desarrollo mundial de la segunda posguerra. 
Aunque la ecuación conservadores $=$ terratenientes Vs. liberales $=$ comerciantes e industriales no se cumplió en los términos clásicos, lo cierto es que la gran propiedad territorial si se constituyó en un obstáculo para el mejor desarrollo general de capitalismo, tal como lo había descrito David Ricardo, razón por la cual desde la segunda mitad de la década de los 30 algunos liberales venían promoviendo reformas democratizantes como la Ley 200 de 1936 o Ley de Tierras, enterrada por los conservadores con la ley 100 de 1944.

Esta pugna por una vía rápida de desarrollo del capitalismo en el campo, basada en la pequeña y la mediana propiedad, enfrentada a la defensa de la gran propiedad y a su lenta transformación en hacienda capitalista, en función de las complejas estructuras de los poderes locales generó una violencia creciente en los campos propiciada por bandas armadas de sello partidista ("chulavitas", "pájaros"...) que afectaban la estabilidad institucional, llevando inclusive al exilio a los dirigentes de los partidos.

En ese marco. A finales de los años 50 se pactó en España un acuerdo bipartidista llamado el "Frente Nacional", mediante el cual liberales y conservadores se turnarían en el poder cada cuatro años, durante cuatro períodos. Esta "alternación" estaba complementada con la "milimetría" en el reparto de los cargos públicos (mitad y mitad para cada partido), y con la exclusión de cualquier fuerza política diferente de los dos partidos tradicionales de las contiendas electorales. Con ello se esperaba pacificar el país y producir las reformas institucionales requeridas para armonizar el desarrollo nacional con el modelo internacional (importación de bienes de capital y exportación de café, banano, carne y otros productos; y de materias primas para la industria).

Por la misma época triunfó la revolución cubana y los Estados Unidos de Norteamérica respondieron con la estrategia de la Alianza para el Progreso, proponiendo la "década del desarrollo" creciente y sostenido para los países "subdesarrollados". Colombia entró así en la euforia del desarrollo entendido como crecimiento económico y se acogió a la condición de recibir ayuda económica a cambio de ajustar su modelo mediante la aplicación de Planes de Desarrollo centralizados. Este proceso de ordenamiento institucional se cumple, en lo fundamental, con la reforma constitucional de 1968, período durante el cual el Presidente Carlos Lleras Restrepo hace el último intento para introducir una vía rápida de desarrollo capitalista en el campo con la Reforma Agraria, proyecto que es derrotado nuevamente.

El balance a la finalización del Frente Nacional, 16 años después de haberse iniciado en 1958, puede ser resumido así: un ordenamiento institucional favorable al desarrollo lento del capitalismo en la agricultura y en la industria; una amplia masa de campesinos pobres y parcelarios sin tierra, ligados a una importante masa de proletariado agrícola, que todavía hoy no se acaba de descomponer en fuerza libre de trabajo y que nutre nuestros campos de productores y cosechadores de coca y de combatientes para las guerrillas y los paramilitares y nuestras ciudades de población desplazada por la violencia; unas guerrillas fortalecidas por el hecho de haberse cerrados los canales de participación oposición y para la construcción de alternativas democráticas; una izquierda reprimida y desarticulada durante los años 70 y una ciudadanía 
desmotivada y abiertamente antipolítica por los excesos de la burocratización, la corrupción y el clientelismo; el surgimiento del narcotráfico como el fenómeno de mayor impacto social, económico, político y cultural de los últimos años; la vinculación del narcotráfico a la guerra contra la insurgencia armada y el surgimiento de los grupos paramilitares de origen diverso en distintas regiones del país; la eliminación física de los dirigentes políticos de oposición con proyección nacional como alternativas unitarias de convergencia de amplios sectores democráticos. Pero, por sobre todas las cosas, una enorme expectativa de que con el libre juego democrático, más allá de los dos partidos tradicionales, se abría el campo para la irrupción de terceras fuerzas capaces de acabar con las hegemonías establecidas y consolidadas durante esos 16 años.

\section{GF: ¿Cuáles son los grupos involucrados y como se sitúan hoy?}

OPC: El balance anterior permaneció casi sin modificaciones hasta la década de los 90 cuando los ajustes capitalistas que acompañaron la finalización de la Guerra Fría introdujeron la lógica del mercado y propiciaron la aparición de las tendencias neoconservadoras $u$ neoliberales que hoy se implementan en nuestros países. La década de los 80 frustró por la violencia estatal y paramilitar los intentos de consolidación de alternativas unitarias dando como resultado no sólo la consolidación de las guerrillas existentes más importantes (FARC - ELN, entre otros), sino la aparición de grupos nuevos como el M-19, nacido de una polémica derrota electoral de la Alianza Nacional Popular ANAPO-, en plena finalización del Frente Nacional.

La vinculación del narcotráfico con los grupos paramilitares y la lucha por el control del territorio generó una escalada de violencia que recordó los peores tiempos de "la violencia". Las fuerzas paramilitares se unificaron políticamente bajo el nombre de Auto Defensas Unidas de Colombia -AUC- aunque siguieron operando de acuerdo con sus estructuras regionales independientes (Antioquia, Córdoba, Llanos Orientales, Urabá, Catatumbo, centros urbanos como Barrancabermeja, y comunas en Medellín y Bogotá, entre otras) las cuales responden a procesos locales diversos, ligados con intereses también diferentes que coinciden, básicamente, en su decisión de enfrentar a las guerrillas. Estos grupos desalojaron por métodos extremadamente violentos a las guerrillas de sitios tradicionalmente ocupados por ellas, incursionando en primer lugar contra la población civil, la cual fue objeto de asesinatos masivos, torturas, amenazas, secuestros, desplazamiento y confinamiento. Se calcula que en este momento hay más o menos unos tres millones de personas desplazadas por este tipo de violencia en el país. Las represalias de la guerrilla a este tipo de acciones reprodujeron la misma lógica en las zonas dominadas por las autodefensas. Ambos, guerrillas y autodefensas disputaron territorios claves para la producción y el procesamiento de la coca, principal fuente de sus cuantiosos recursos.

El M-19 se desmovilizó junto con otros grupos como el Ejército Popular de Liberación EPL- de orientación marxista leninista (maoísta) y en el gobierno de Andrés Pastrana se da un proceso de diálogo fallido que implicó la definición de una zona de distensión dentro de 
la cual las FARC se replegaron y fortalecieron, dando lugar a un movimiento nacional de opinión que llevó a la presidencia a Álvaro Uribe Vélez, quien fue crítico del proceso y se presentó como alternativa de fuerza para derrotar militarmente a la guerrilla.

El ELN se ha manifestado partidario de una salida negociada aunque el proceso avanza poco; las FARC insisten en sentarse a dialogar previo establecimiento de una zona desmilitarizada y no aceptan las propuestas del gobierno para negociar en el exterior. En este momento, el gobierno avanza en un proceso de desmovilización de las autodefensas que no es claro para amplios sectores de la población y que es abiertamente cuestionado por las FARC. Sobre este punto no hay una ruta de llegada claramente establecida, dejando en la incertidumbre el efecto político inmediato y de mediano plazo. Las autodefensas se han visto enfrentadas internamente mientras su expresión parlamentaria (porque tienen expresión parlamentaria y presencia en gobiernos locales) hace lobby político para fortalecer la negociación con el gobierno.

\section{GF: ¿Quién o quienes pagan la cuenta o quienes son los más violentados?}

OPC: La población desplazada puede ser considerada la materialización dramática de los costos de una guerra que el actual presidente de la república se empeña en negar. El fenómeno es visible prácticamente en todas las grandes ciudades del país. Sin embargo la población desplazada no es la única. El desempleo ha aumentado de manera dramática ampliando el ejército de desocupados no solo en los sectores populares (los llamados estratos 1 y 2) sino en las capas medias (estratos 3 y 4), golpeadas también por la pérdida de valor adquisitivo de sus salarios. La política social de Estado se ha visto restringida por la orientación del gasto social al gasto militar y por la insistencia en ajustar el régimen pensional, el régimen tributario y los servicios públicos en función de las exigencias del FMI y del BM. Mientras tanto el sector financiero muestra índices crecientes de utilidades y la brecha entre ricos y pobres se hace cada vez más profunda. No hay duda sobre quienes estamos pagando la cuenta de la guerra y del conflicto.

\section{GF: ¿Qué perspectiva hay de solución y de qué depende?}

OPC: El gobierno norteamericano apoya decididamente al gobierno colombiano a través del Plan Colombia y su continuación mediante el Plan Patriota, factor de gran importancia dado el triunfo de Bush y el ambiente favorable a la reelección de Uribe para el próximo período. Se dice que la embajada de los Estados Unidos en Colombia está entre las tres más grandes del mundo.

La guerrilla sigue replegada y el ejército no muestra resultados contundentes desde el punto de vista militar. Mientras tanto, las fuerzas alternativas solamente alcanzan triunfos electorales locales, algunos importantes como en los casos de las alcaldías de Bogotá y Medellín y la Gobernación del Valle del Cauca, pero no logran unificar todo el campo de la izquierda democrática. 
La posibilidad de una solución inmediata a los conflictos no es clara El escenario así configurado es de alta incertidumbre y entropía, obligando a una análisis pormenorizado de las correlaciones de fuerzas para la determinación de las líneas de acción. En general, se puede decir que hay un marcado reflujo en la movilización social, que las políticas neoliberales avanzan en educación, salud y pensiones. Se insiste en la reforma tributaria y se avanza en las negociaciones relacionadas con el ALCA y el TLC, aunque hay posiciones cautas en relación con el tema agrícola, por ejemplo. Los sectores sociales ligados a procesos de movilización están desarticulados aunque se avanza en propuestas de unificación de acciones. Por otro lado, es importante destacar que el escenario internacional es decisivo para el análisis de las posibilidades internas. Creemos firmemente que el futuro de los movimientos alternativos en el poder está directamente ligado a la existencia de, por lo menos, un ambiente internacional favorable, cuando no de una concertación democrática amplia que garantice no solo el acceso al poder sino la posibilidad de mantenerse en él durante un período de tiempo lo suficientemente largo como para consolidar transformaciones irreversibles. Con esto no se quiere decir que la solución dependa totalmente del contexto internacional. La salida tendrá que seguirse buscando internamente pero el factor internacional seguirá teniendo un peso importante. De allí el interés que tiene para nosotros lo que pueda ocurrir con el gobierno de Lula y con las fuerzas políticas que gravitan en torno a él. Lo que está en juego no es sólo el futuro inmediato de Brasil. Nuestros procesos internos se verían seriamente afectados si su propuesta alternativa no se consolida. Eso también es un mensaje para él.

[1] . Entrevista feita em 27.11.2004.

volta 